\title{
Formas de revolução e cálculo de volume
}

\author{
Revolution shapes and volume calculation
}

Sérgio Carrazedo Dantas ${ }^{1}$ e Carmen Vieira Mathias ${ }^{2}$

\author{
${ }^{1}$ UNESPAR, Brasil \\ sergio@maismatematica.com.br \\ ${ }^{2}$ Universidade Federal de Santa Maria, RS, Brasil \\ carmen@ufsm.br
}

\section{Resumo}

Neste trabalho apresentam-se propostas de atividades que podem ser desenvolvidas com alunos do Ensino Médio, para determinar formas de revolução, bem como o volume das mesmas. O objetivo principal ao desenvolver as atividades foi produzir reflexões sobre uma maneira de calcular volume de sólidos de revolução quaisquer sem utilizar conceitos de Cálculo Diferencial e Integral ou utilizando as formas clássicas de cálculo de volume. Pretende-se, com a abordagem por meio do software GeoGebra, mostrar diferentes maneiras de trabalhar conceitos matemáticos, que em geral não são desenvolvidos em cursos regulares, contribuindo com a disseminação do uso deste recurso tecnológico na resolução de problemas matemáticos presentes no cotidiano.

Palavras-chave: volume; formas de revolução; GeoGebra

\section{Abstract}

In this paper we present proposals for tasks that can be developed with high school students, to determine forms of revolution, and the volume of them. The main objective in developing the activities, was to determine a way to calculate volume of solids of any revolution, without using concepts of Differential and Integral Calculus or using the classic forms of volume calculation. The aim of the approach through the Geogebra software, shows different ways of working mathematical concepts, which generally are not developed in regular courses, contributing to widespread the use of this technological resource in solving everyday mathematical problems.

Keywords: Volum; Revolution shapes; GeoGebra 


\section{Introdução}

É possível determinar o volume de uma forma obtida por meio de uma revolução sem que para isso sejam necessários conhecimentos de Cálculo Diferencial ou sem recorrer às "fórmulas clássicas" para o cálculo de volume?

Ao trabalhar com alunos ingressantes na universidade, em particular na disciplina de Cálculo Diferencial e Integral, os autores deste texto observam, dentre outras, dificuldades na resolução de problemas envolvendo o cálculo de volume de formas de revolução. Uma das principais dificuldades está em esboçar ou visualizar uma forma de revolução e em escolher um método apropriado para determinar seu volume, principalmente quando essas formas são discos ou cascas cilíndricas.

Alguns pesquisadores brasileiros, Cury e Bisognin (2006), que investigaram as causas de dificuldades, como as mencionadas, afirmam que os estudantes trazem de escolarizações anteriores algumas defasagens que podem comprometer a resolução de problemas quando os procedimentos envolvem conhecimentos sobre geometria. Nesse mesmo sentido, Balomenos, Ferrini-Mundy e Dick (1994) afirmam que muitas noções necessárias para a compreensão do Cálculo Diferencial e Integral baseiam-se no curso tradicional de Geometria da Educação Básica.

Assim, acredita-se que muitos estudantes compreendem a aplicação das fórmulas tradicionais para o cálculo de volume de um prisma retangular, de um cilindro ou de um cone que são, geralmente, apresentadas em materiais didáticos. Embora, em muitos casos, as "fórmulas" para cálculo de volume não são devidamente justificadas por muitos autores desses materiais didáticos. Percebe-se ainda que o conhecimento dos estudantes sobre cálculo de volume se limita a aplicações das tais fórmulas, não conseguindo utilizá-lo em situações envolvendo formas que não se assemelham às tradicionais (cubo, paralelepípedo, cilindro, cone e esfera).

A partir dessas impressões e das leituras de estudos sobre esse fenômeno, tem-se por objetivo apresentar neste texto uma sequência de atividades ou exemplos para promover reflexões sobre o estudo de volume de formas de revolução e seu alcance no que diz respeito a aplicações em situações cotidianas. Toma-se como problema motivador a determinação do volume de uma lata de refrigerante.

Para atingir os objetivos, apresenta-se como construir formas de revolução (cilindro, cone, tronco de cone e outras não padronizadas) utilizando o GeoGebra. Em seguida, faz-se uma breve discussão sobre o Princípio de Cavalieri para justificar o cálculo de volume de um cilindro quando comparado a um prisma retangular. E, depois, é apresentado o Teorema de Pappus como alternativa para o cálculo de volume de um cilindro.

Por último, apresenta-se uma maneira de construir objetos tridimensionais a partir de suas silhuetas, ou seja, a partir de figuras planas obter formas tridimensionais por revolução. E, aliado a isso, é apresentado um procedimento realizado no GeoGebra que aplica o Teorema de Pappus ao cálculo de volume de objetos obtidos por revoluções.

As construções apresentadas neste texto utilizam ferramentas e comandos do GeoGebra, cujas sintaxes são abordadas por meio das demonstrações de resultados e ilustrações.

Mantém-se a expectativa de que o leitor realize as construções propostas, reflita sobre as aplicações do cálculo de volume e aplique essas noções em aulas de Matemática.

\section{Construções de formas de revolução}

Segundo Rautenberg (2013), as formas de revolução podem ser obtidas pela rotação de uma região de um plano em torno de uma reta desse plano, chamado eixo de revolução ou rotação, que toca a fronteira da região ou não intersecta a região em nenhum ponto. Em Dantas (2015) é descrito um processo de construção de formas de revolução no GeoGebra a partir de polígonos. Inspirado nesse processo, apresentam-se no texto que segue os principais comandos necessários à construção de um cilindro de revolução.

Para iniciar a construção, devem-se construir quatro pontos livres: A, B, C e D, conforme apresentado na Figura 1.

Esses pontos são os vértices do polígono $\mathrm{ABCD}$, que pode ser construído com o mouse ou digitando-se no Campo Entrada o comando: Polígono[A, B, C, D]. O GeoGebra retornará um polígono que será nomeado automaticamente de pol1.

Sugere-se clicar com o botão direito do mouse sobre a Janela de Visualização e acessar a opção Malha para torná -la visível, o que pode facilitar a tarefa de arrastar os pontos para coordenadas específicas, formando um retângulo, conforme apresentado na Figura 2.

Nos próximos passos obtém-se um conjunto de imagens do retângulo $\mathrm{ABCD}$ por meio de giros. Antes, porém, deve-se exibir a Janela de Visualização $3 \mathrm{D}^{1}$, caso a mesma ainda não esteja exibida. Para isso, deve-se acessar o menu Exibir e clicar na opção Janela de Visualização 3D.

Utilizando o comando Girar[<Objeto $>,<$ Ângulo $>,<$ Eixo de Rotação $>$, constrói-se uma imagem do polígono poll no plano xz da Janela de Visualização 3D. Para isso, deve-se substituir o parâmetro $<$ Objeto $>$ por pol1, $<$ Ângulo $>$ por $\pi / 2$ e $<$ Eixo de Rotação $>$ por EixoX, ou seja, Girar[pol1, $\pi / 2$, EixoX], cujo resultado é um novo polígono (pol2), quando digitado na Caixa Entrada (Figura 3).

1 Recomenda-se Andrade (2015) como referência sobre os recursos da Janela de Visualização $3 D$. 


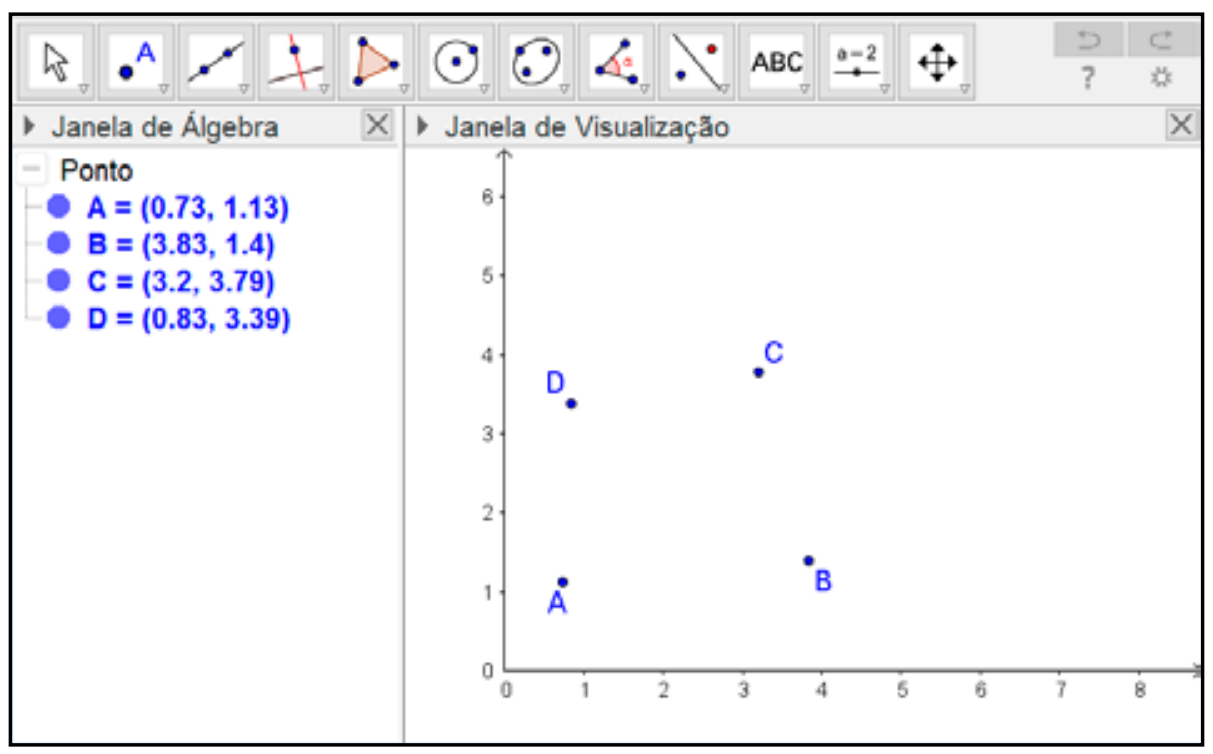

Figura 1 - Pontos A, B, C e D na Janela de Visualização

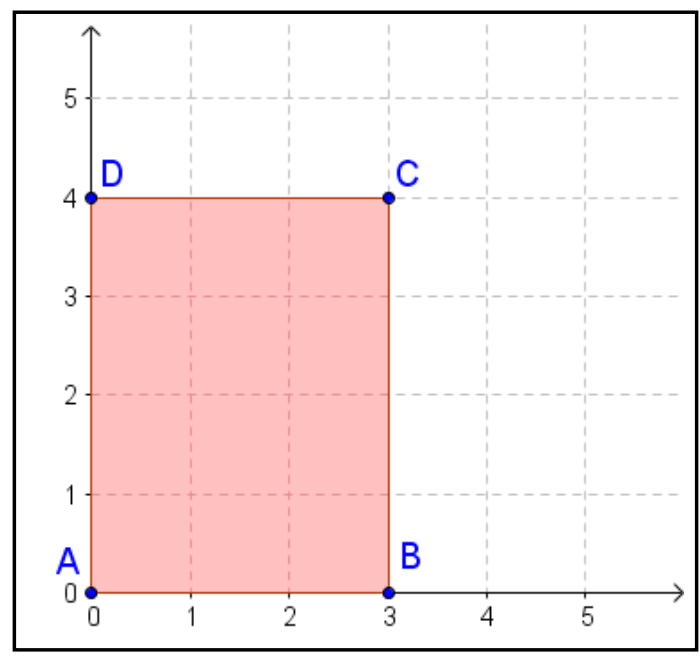

Figura 2 - Polígono ABCD exibido sobre a malha quadriculada do GeoGebra

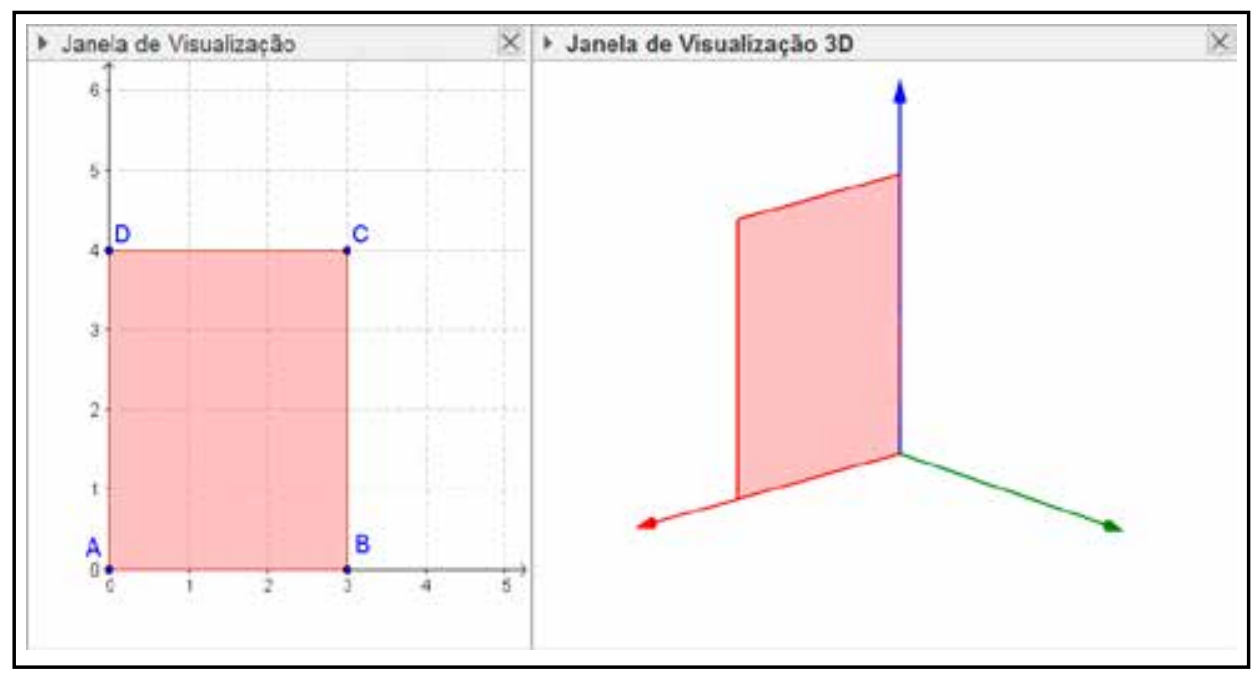

Figura 3 - Polígonos pol1 na Janela de Visualização e pol2 na Janela de Visualização 3D 
O quadrilátero visualizado na Janela de Visualização 3D corresponde à imagem obtida ao girar em $90^{\circ} \mathrm{o}$ pol1 em torno do Eixo X que, na Janela de Visualização 3D, corresponde ao eixo na cor vermelha. O Eixo y é indicado em verde, e o eixo $z$ em azul.

O passo seguinte consiste em obter várias "cópias" de pol2 por diferentes giros em torno do Eixo Z. Para realizar essa ação, utilizam-se os comandos Sequência e Girar conjuntamente.

O comando Sequência possui a seguinte sintaxe:

Sequência[<Expressão $>$, < Variável $>$, < Valor Inicial $>,<$ Valor Final $>,<$ Incremento $>]$

Com esse comando é possível construir sequências numéricas, algébricas e geométricas. Em outras palavras, conforme Dantas e Ferreira (2014), tal comando permite criar uma família finita de objetos.

Retomando a construção, antes de digitar o comando Sequência no Campo Entrada, constrói-se um controle deslizante n (com mínimo 0, máximo 100 e incremento 1), que serve de parâmetro numérico para a produção da lista de objetos do comando Sequência. Em seguida, digita-se a expressão de comandos combinados no Campo Entrada:

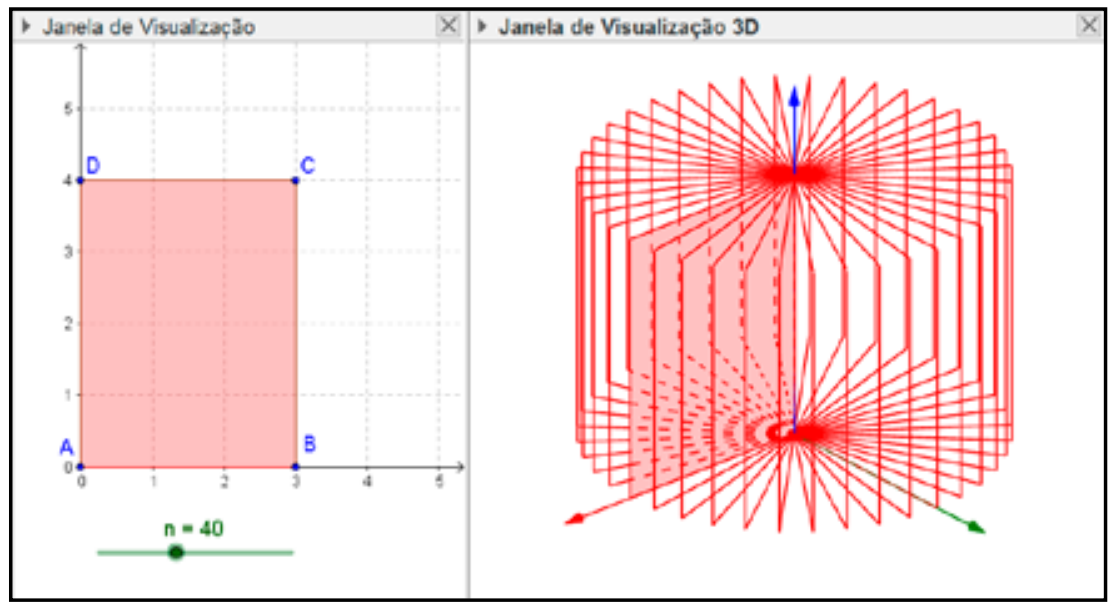

Figura 4 - Forma que lembra um cilindro de revolução

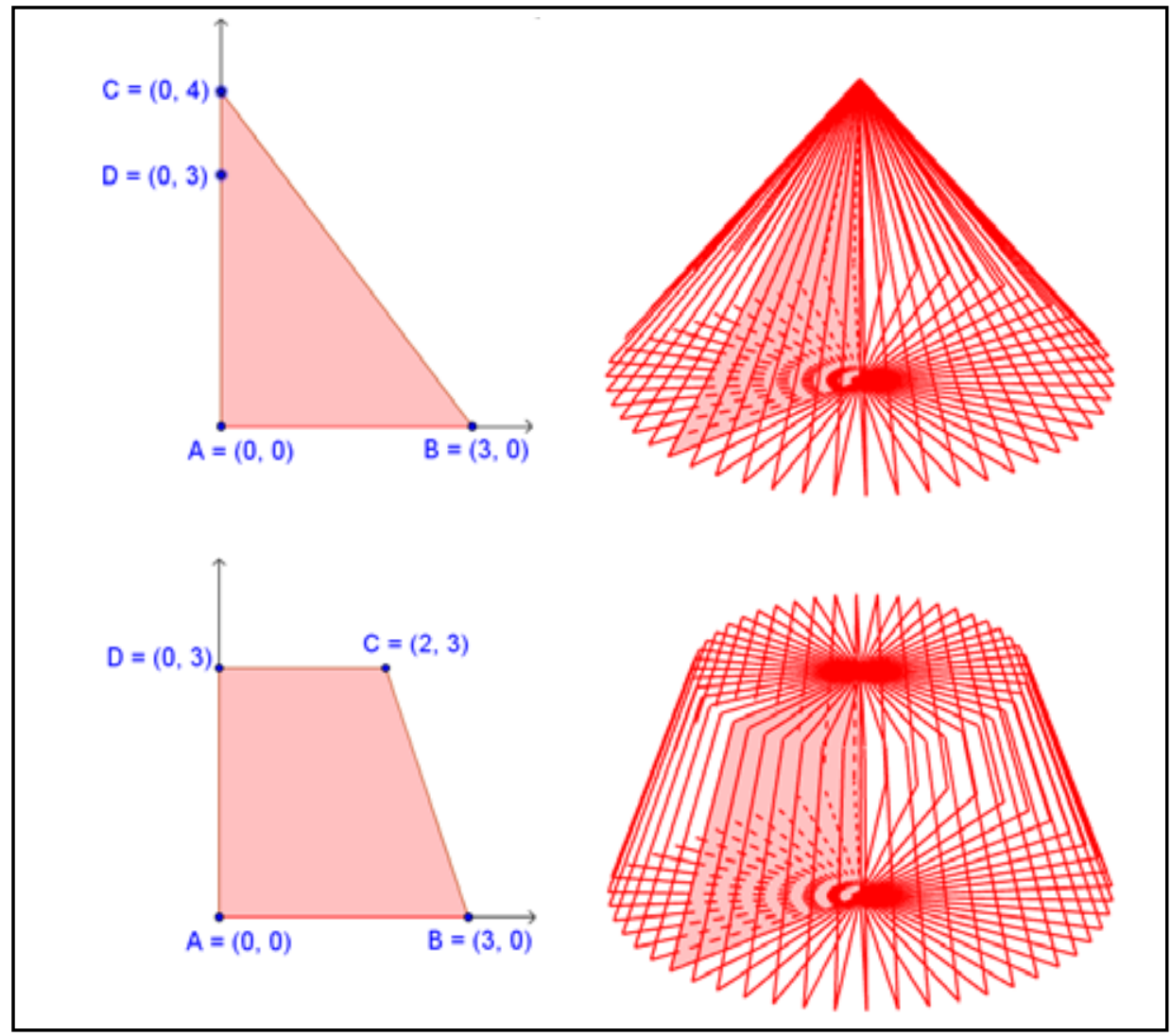

Figura 5 - Formas que lembram um cone e um tronco de cone 


\section{Sequência[Girar[pol2, i $2 \pi / n$, EixoZ], i, 0, n]}

O comando Sequência, com os parâmetros apresentados anteriormente, é baseado na variável i, que assume valores de 0 até $\mathrm{n}-1$. Como a expressão do comando Sequência é também um comando, Girar[pol2, i $2 \pi / \mathrm{n}$, EixoZ], para $\mathrm{i}=0$ é obtida uma imagem do pol2 com um giro de 0 em torno do eixo $z$, para $i=1$ é obtida uma imagem do pol2 com giro de $2 \pi / \mathrm{n}$ em torno do eixo z e assim sucessivamente com incremento $2 \pi / \mathrm{n}$. Observa-se na Figura 4 o resultado para $\mathrm{n}$ assumindo valores de 0 a 40 .

A opção por deixar os pontos A, B, C e D livres, ao invés de atrelá-los a uma forma geométrica pré-definida (no caso um retângulo), permite modificar suas coordenadas de tal modo a obter formas de revolução que lembrem o cone, o tronco de cone, entre outras.

\section{Cálculo de volume}

Em materiais didáticos voltados para o Ensino Médio (LIMA et al. (2006), DANTE (2010), PAIVA (2009)), o volume do cilindro, da esfera e de outras formas de revolução é geralmente calculado utilizando-se o Princípio de Cavalieri, que afirma:

Dados dois sólidos e um plano. Se todo plano paralelo ao plano dado secciona os dois sólidos segundo figuras de mesma área, então, esses sólidos têm mesmo volume (LIMA et al. 2006, p. 285).

A figura 6 ilustra tal fato em que um cilindro e um prisma de base retangular e alturas iguais possuem secções de mesma área por qualquer plano $\beta$ paralelo a $\alpha$.

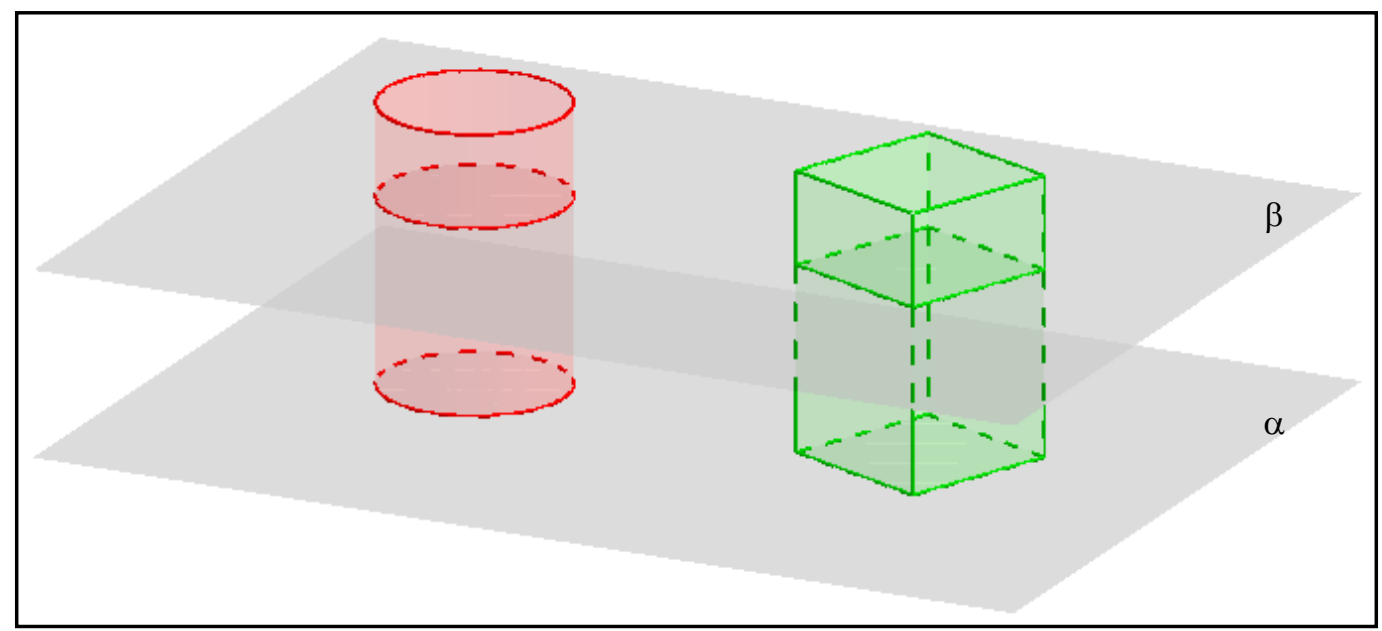

Figura 6 - Um cilindro e um cone seccionados por um plano $\beta$ paralelo a um plano $\alpha$

A partir do que é ilustrado na Figura 6 pode-se calcular o volume do cilindro circular comparando-o com o prisma cuja seção transversal retangular tenha área igual à seção transversal do cilindro pelo mesmo plano.

Embora o Princípio de Cavalieri seja útil para deduzir as expressões para cálculo de volume de outras formas de revolução, apresenta-se outra possibilidade para realizar esses cálculos utilizando o Teorema de Pappus ${ }^{2}$ para o cálculo de volume:

Se uma figura plana gira em torno de um eixo de seu plano, o volume (V) gerado é igual ao produto da área dessa figura (S) pelo comprimento da circunferência descrita pelo seu baricentro ( $2 \pi d$ ) (LIMA et al. 2006, p. 284).

O volume da forma de revolução apresentada na Figura 7, utilizando o Teorema de Pappus, é obtido realizando a multiplicação da área da figura plana (S), pela distância (d) e por $2 \pi$, ou seja, V = S.d. $2 \pi=2 \pi \mathrm{dS}$.

As expressões para o cálculo de volume de cilindros também podem ser obtidas a partir da área do polígono que sofreu a revolução, multiplicado pela distância do seu baricentro ao eixo de rotação, multiplicado por $2 \pi$. Esse processo consiste em realizar o cálculo por meio do Teorema de Pappus, que é apresentado a seguir.

Para iniciar, retoma-se a construção da forma de revolução realizada no GeoGebra e redefinem-se as coordenadas dos pontos para $A=(1,0), B=(3,0), C=(3,3)$ e $D=(1,3)$, obtendo a forma de revolução apresentada na Figura 8 .

Uma maneira de calcular o volume dessa forma consiste em considerar a diferença do volume de dois cilindros, um de raio $3 \mathrm{~cm}$ e outro de raio $1 \mathrm{~cm}$, ambos com $3 \mathrm{~cm}$ de altura ${ }^{3}$.

2 Neves (2013) utiliza o Teorema de Pappus e princípios de modelagem matemática para determinar o volume de uma maçã.

3 Essas medidas foram obtidas em função das coordenadas dos pontos A, B, C e D que determinam o retângulo girado em torno do eixo Z. 


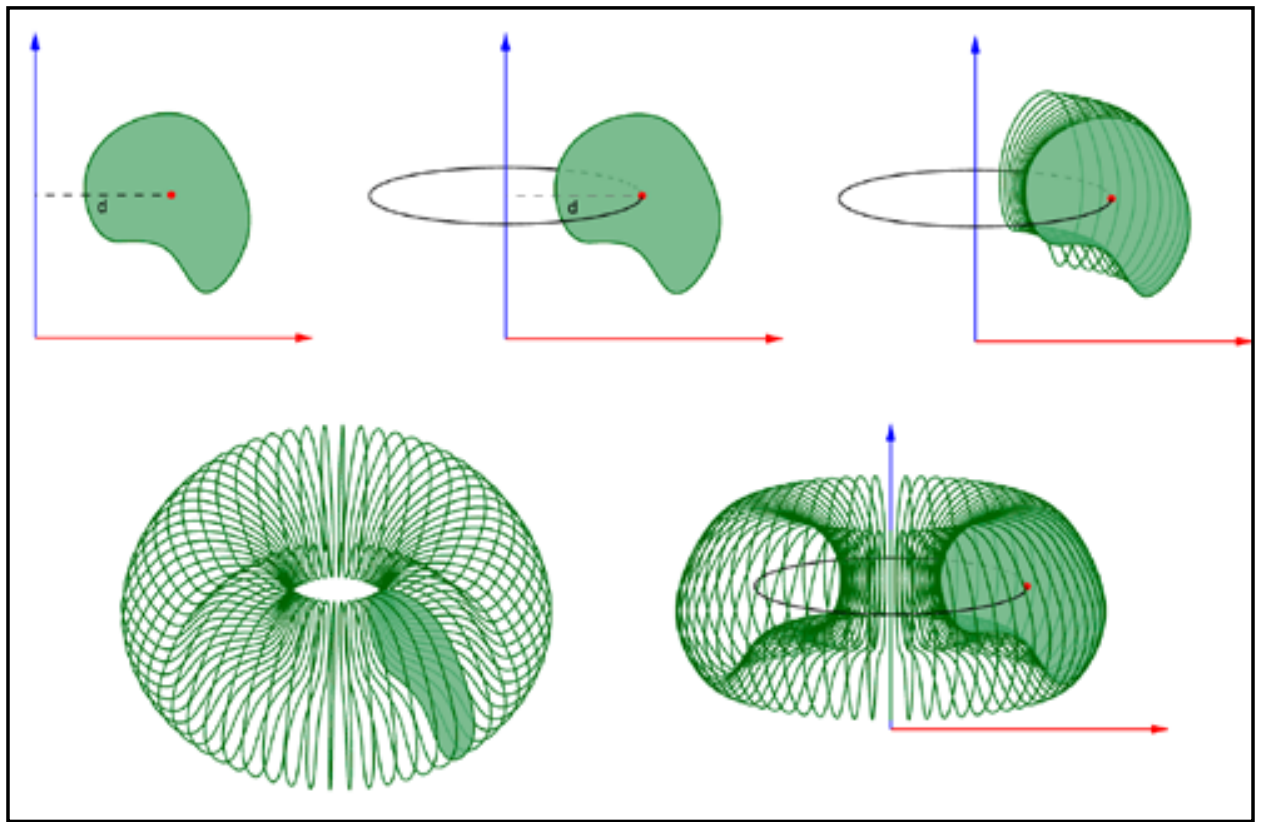

Figura 7 - Figura plana girando em torno do eixo y para obter uma forma de revolução

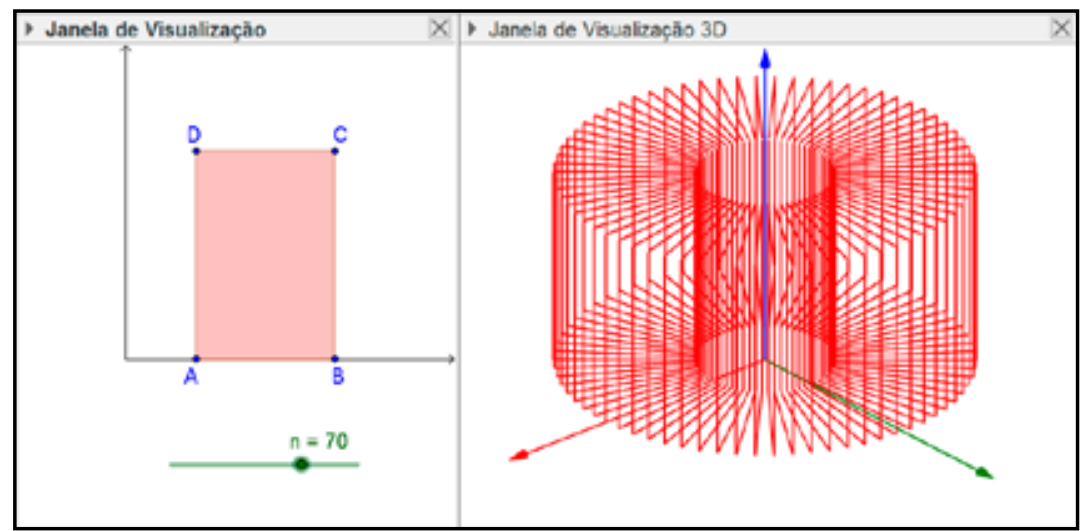

Figura 8 - Forma de revolução obtida pelo giro do polígono ABCD em torno do eixo y

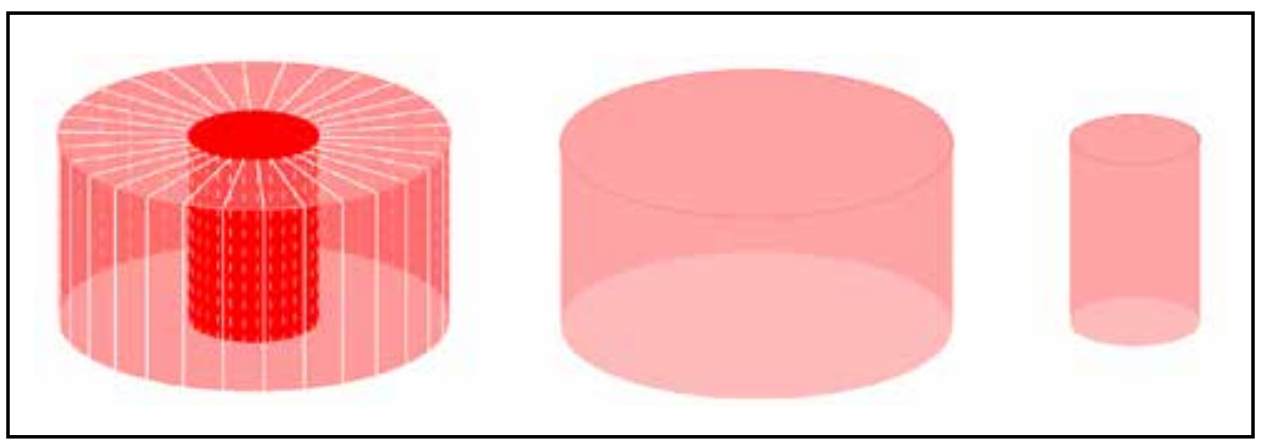

Figura 9 - Três cilindros 
Nesse caso, o volume da forma de revolução é calculado por:

$$
\mathrm{V}=\pi \cdot 3^{2} .3-\pi \cdot 1^{2} \cdot 3=27 \pi-3 \pi=24 \pi
$$

Observa-se que esse processo pode ser generalizado. Para isso, consideram-se os pontos $A=(a, 0), B=(a+b, 0)$, $C=(a+b, h)$ e $D=(0, h)$, conforme apresentado na Figura 10.

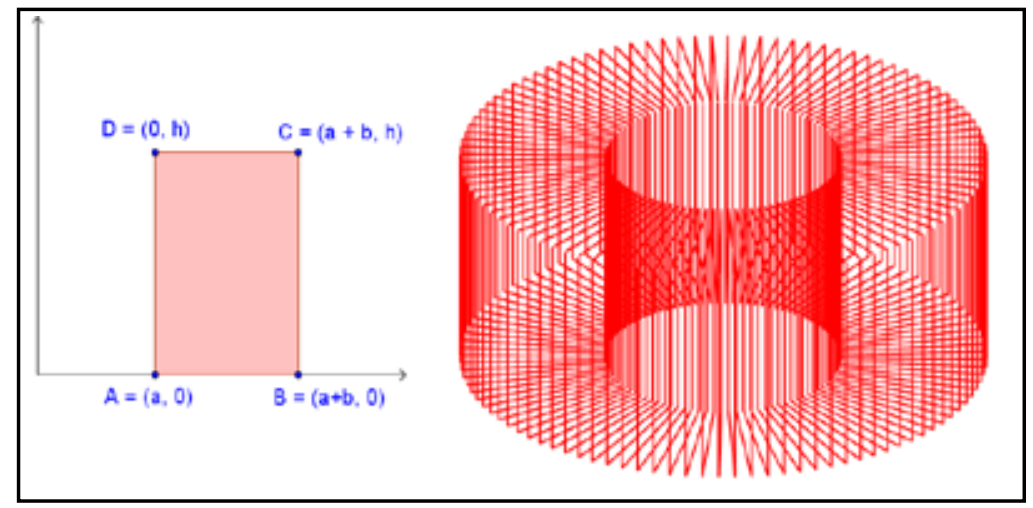

Figura 10 - Generalização do processo de cálculo de volume

O cálculo do volume da forma de revolução obtida pode ser realizado a partir do volume de dois cilindros, um de raio $a+b$ e outro de raio $b$, e a altura $h$ para ambos. Assim, o volume da forma de revolução é obtido por meio do seguinte cálculo:

$$
\mathrm{V}=\mathrm{V}_{\text {maior }}-\mathrm{V}_{\text {menor }}=\pi(\mathrm{a}+\mathrm{b})^{2} \cdot \mathrm{h}-\pi \mathrm{b}^{2} \cdot \mathrm{h}=\pi \mathrm{a}^{2} \mathrm{~h}+2 \pi \mathrm{abh}+\pi \mathrm{b}^{2} \mathrm{~h}-\pi \mathrm{b}^{2} \mathrm{~h}=2 \pi \mathrm{ah}\left(\frac{\mathrm{a}}{2}+\mathrm{b}\right)
$$

O fator ${ }_{\left(\frac{a}{+}\right)}$ que compõe a expressão final do volume calculado anteriormente corresponde à abcissa do baricentro $^{4}\left(\frac{-{ }^{+b}}{}\right)$ (centro de gravidade) do polígono $\mathrm{ABCD}$, e $\mathrm{S}=$ ah é a área do polígono. Dessa forma, o volume pode ser reescrito como $\mathrm{V}=2 \pi \mathrm{dS}$. Essa forma de cálculo corresponde a uma aplicação do Teorema de Pappus ${ }^{5}$ para o cálculo de volumes.

Para calcular o volume da forma de revolução obtida na Figura 10, foi necessário obter seu baricentro utilizando comando $O=$ CentroDeGravidade[pol1]. Observa-se que a expressão para o cálculo do volume, segundo o Teorema de Pappus, é dada por

\section{$\mathrm{V}=2 \pi$. [distância do baricentro ao eixo de rotação] . [área do polígono]}

Assim, essa expressão deve ser escrita com a seguinte sintaxe no Campo Entrada do GeoGebra:

$$
\mathrm{V}=2 \pi^{*} \mathrm{x}(\mathrm{O}){ }^{*} \text { pol1 }
$$

em que $\mathrm{x}(\mathrm{O})$ é a abscissa do baricentro do polígono, ou seja, a distância do baricentro ao eixo de rotação, e pol1 é o nome do polígono que, numericamente no GeoGebra, corresponde à área do polígono.

Transladando-se horizontalmente os pontos A, B, C e D da Figura 10, de maneira que A e D fiquem sobre o eixo $\mathrm{y}$, obtém-se pela revolução em torno do eixo y, um cilindro cujo volume pode ser calculado por $\mathrm{V}=2 \pi * b / 2{ }^{*}$ poll.

Esse processo pode ser realizado para o cálculo de volume de formas de revolução cuja região plana seja um polígono. Um questionamento conveniente a partir daí é o seguinte: Como calcular o volume de uma forma de revolução obtida pelo giro de uma figura não poligonal? Para responder a essa questão, será descrito um processo em que se obtém uma esfera a partir do giro de um semicírculo.

A construção é iniciada por um semicírculo. Para tanto, utilizando a ferramenta Controle Deslizante, determina-se um controle de nome r, com mínimo 0, máximo 10 e incremento 0.1. Em seguida, constrói-se o semicírculo digitando no campo Entrada o comando $c=$ Semicírculo[ $(-r, 0),(r, 0)]$.

Existe a necessidade de marcar o ponto $\mathrm{O}$ digitando $\mathrm{O}=(0,0)$ no Campo Entrada ou construindo-o com o mouse. Nota-se que os objetos construídos aparecem na Janela de Visualização e no plano xy da Janela de Visualização 3D, conforme apresenta a Figura 11.

4 Lemos (2013) aborda como determinar o baricentro de polígonos quaisquer.

5 A demonstração do Teorema de Pappus é abordada em Menezes (2015). 


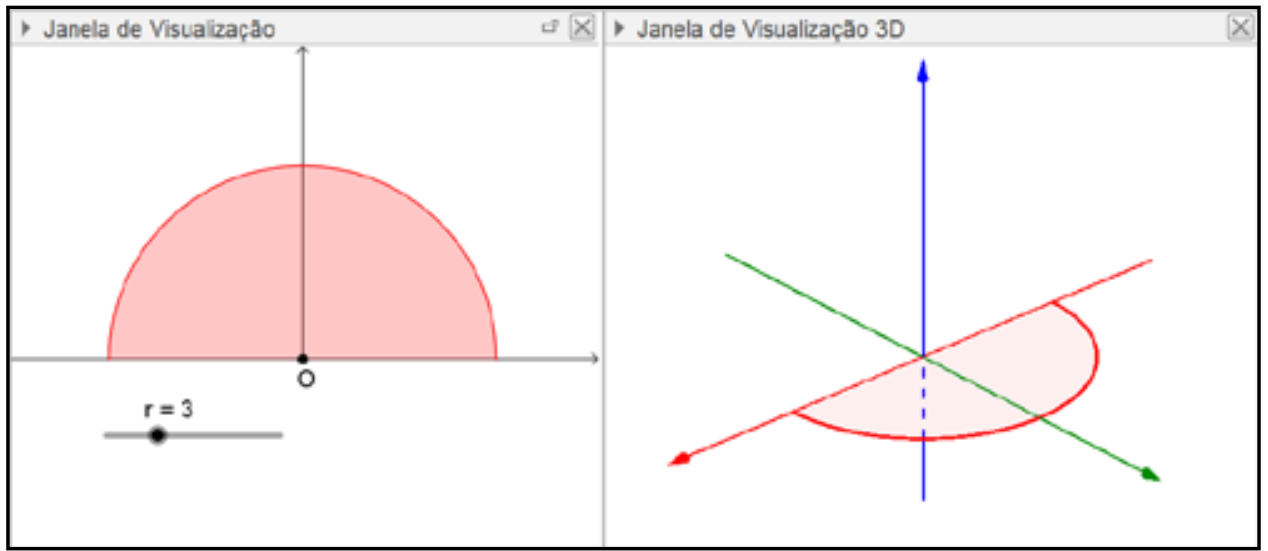

Figura 11 - Construção do semicírculo

Para determinar o volume da esfera a partir do Teorema de Pappus, é necessário determinar o baricentro do semicírculo. Porém, o comando CentroDeGravidade[<Polígono $>]$ do GeoGebra permite determinar apenas o centro de gravidade (baricentro) de polígonos. Para resolver esse problema, constrói-se um polígono sob o arco do semicírculo, cujo comprimento é $\pi \mathrm{r}$, dividindo-o em $\mathrm{n}$ arcos de mesmo comprimento. Inicialmente constrói-se um controle deslizante n, com valor mínimo 1, valor máximo 180 e incremento 1. Em seguida, determina-se uma lista de pontos sobre o traço do semicírculo digitando no Campo Entrada o seguinte comando:

$$
\text { L_1 = Sequência[Girar }[(r, 0), i \pi / n, O], i, 0, n]
$$

A figura 12 ilustra a sequência construída com $n=20$.

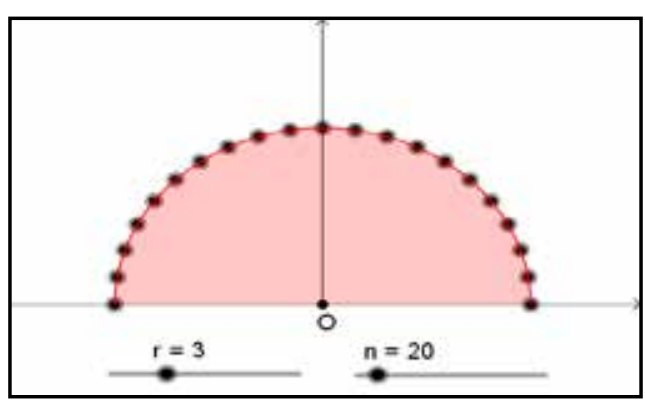

Figura 12 - Representação da sequência de pontos sobre o semicírculo

Em seguida, deve-se construir um polígono tendo como vértices os pontos da lista $\mathrm{L}_{1}$ digitando no Campo Entrada o seguinte comando: pol1 = Polígono[L_1]. Para obter o baricentro de pol1, digita-se G=CentroDeGravidade[pol1].

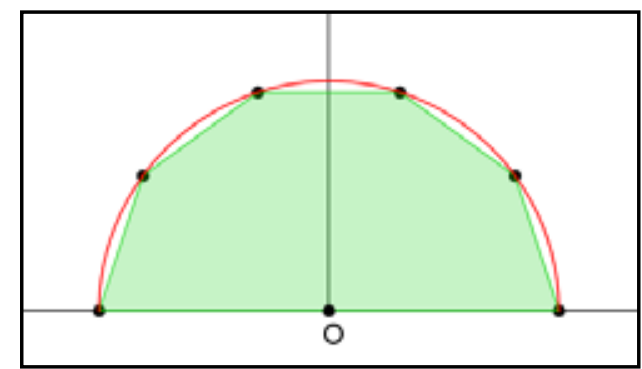

Figura 13 - Construção do polígono e de seu baricentro

Conforme realizado no exemplo anterior, o volume da esfera pode ser determinado via Teorema de Pappus, porém por meio de uma aproximação por polígonos inscritos em um semicírculo e girados em torno do eixo $\mathrm{x}$. 
O volume da esfera é calculado por $\mathrm{V}=2 \pi$. [distância do baricentro ao eixo de rotação] . [área do polígono]. Dessa forma, observando que o eixo de rotação é o eixo x, a distância do baricentro ao eixo de rotação será a ordenada do ponto G; basta digitar $V_{-} 1=2 \pi^{*} \mathrm{y}(\mathrm{G})$ * pol1 no Campo Entrada para obter o volume da esfera.

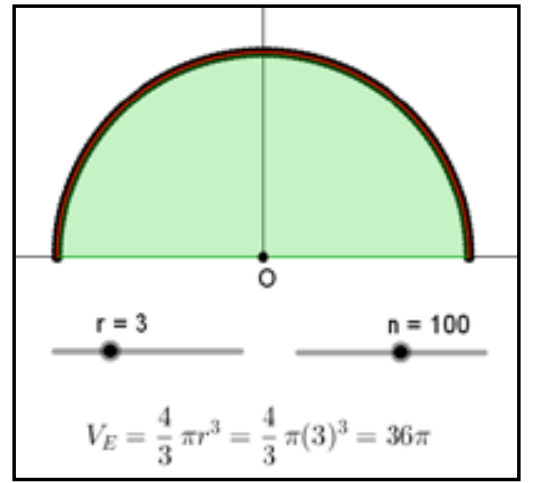

Figura 14 - Cálculo do volume de esferas por meio do Teorema de Pappus

Observa-se que quanto maior o valor de n, melhor a aproximação do volume, como apresentado na Figura 14.

Pode-se ainda construir uma esfera digitando o comando esfera = Esfera[O, r] no Campo Entrada e, em seguida, determinar o seu volume, utilizando o comando $V \_2=$ Volume[esfera].

Observa-se na janela de álgebra que os valores $\mathrm{V}_{1}$ e $\mathrm{V}_{2}$ são muito próximos, conforme apresenta a Figura 15.

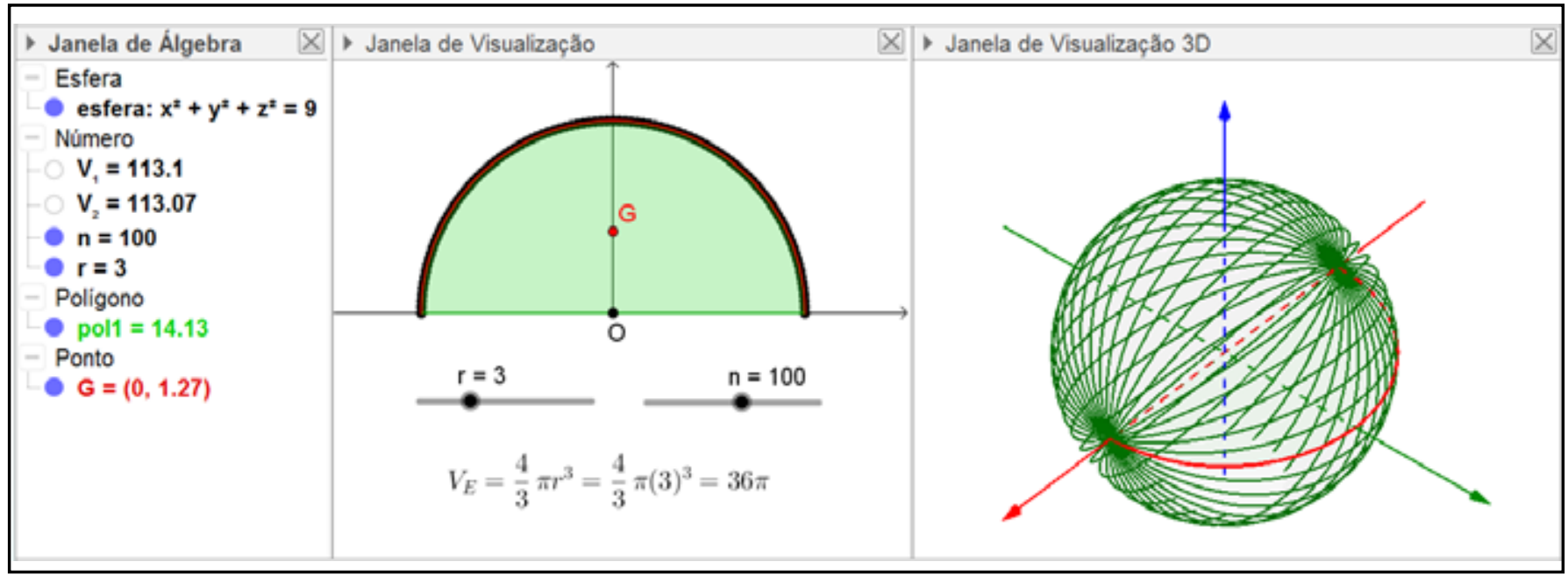

Figura 15 - Construção da esfera

É interessante comparar os valores $\mathrm{V}_{1}$ e $\mathrm{V}_{2}$ à medida que o valor de $\mathrm{n}$ é alterado e perceber que a aproximação dos valores "fica cada vez melhor" à medida que $\mathrm{n}$ "cresce".

Retomando o cálculo do volume do cilindro e da esfera como aplicações do Teorema de Pappus, é possível perceber que, para o cilindro, não houve a necessidade de obter uma aproximação, como foi realizada para a esfera, já que um cilindro pode ser obtido pela revolução de um retângulo. No cálculo do volume da esfera a partir de um semicírculo, a utilização do GeoGebra permitiu colocar em curso "noções de infinitésimos", que permitiram aproximar a área de um polígono de $n$ lados a de um semicírculo.

Utilizam-se essas mesmas ideias de aproximações aliadas a uma modelação 3D, na próxima seção deste texto, descreve-se um exemplo em que se calcula o volume de uma lata de refrigerante.

\section{Modelação de objetos tridimensionais}

Para iniciar a construção, escolhe-se um objeto e se produz uma imagem de sua silhueta. Isso pode ser feito utilizando uma máquina fotográfica ou um smartphone. Em seguida, devem-se obter as medidas do objeto, conforme apresentado na Figura 16. 


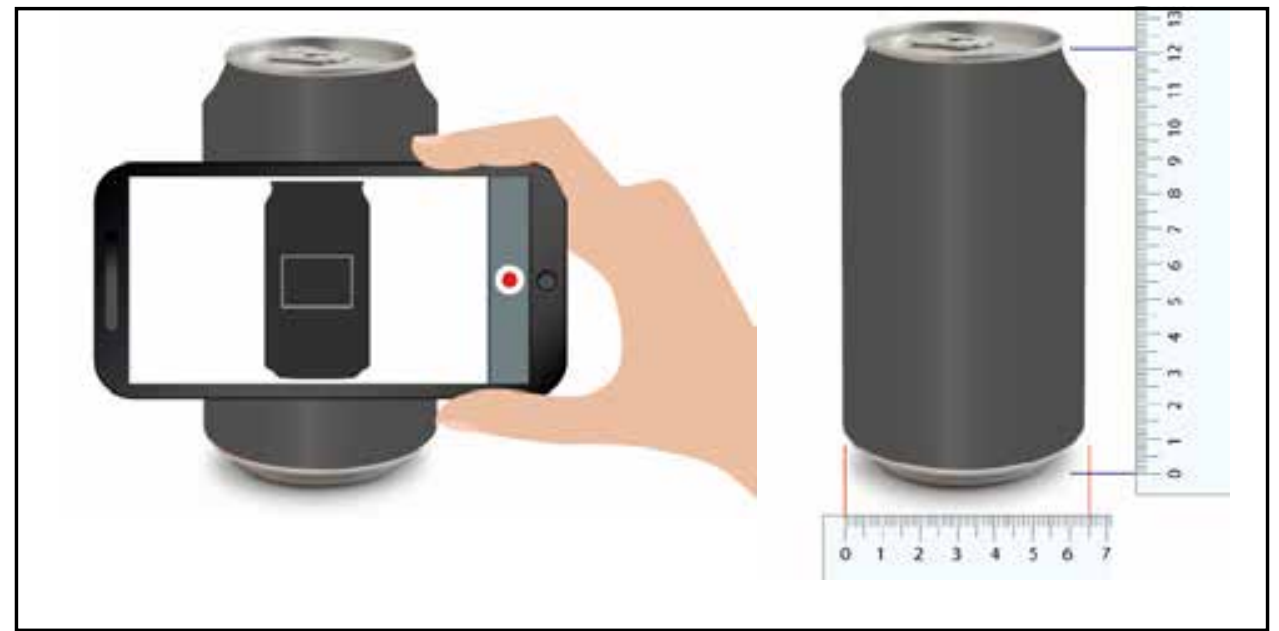

Figura 16 - Medidas do objeto escolhido

Para implementar a construção no GeoGebra, deve-se clicar na ferramenta Inserir Imagem e escolher a imagem na lista de arquivos. Em seguida, posicionam-se os pontos A e B de maneira que a silhueta fique centralizada no eixo y e a imagem preserve o tamanho original do objeto $(6,5 \mathrm{~cm} \times 12,3 \mathrm{~cm})$.

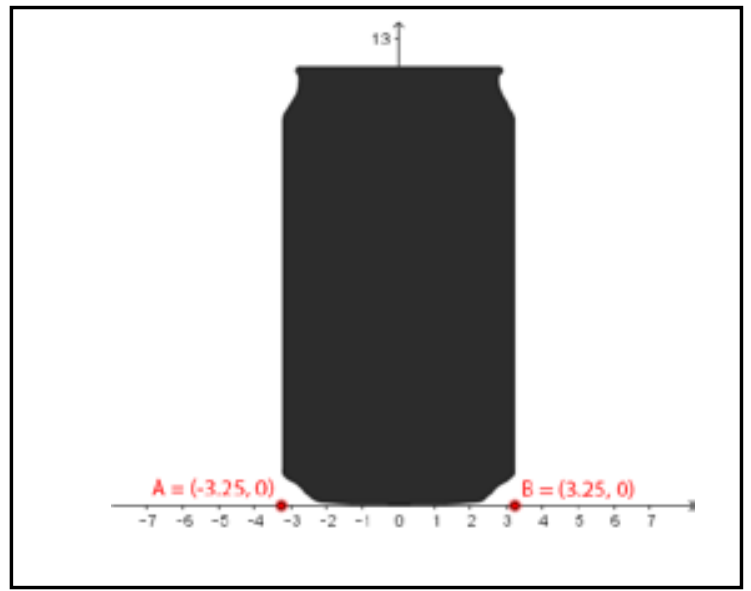

Figura 17 - Posicionamento da figura

No passo seguinte, ocultam-se os pontos A e B e, com a ferramenta Ponto, constroem-se pontos sobre o contorno da silhueta, concentrando uma maior quantidade de pontos nas curvas mais acentuadas do contorno da silhueta.

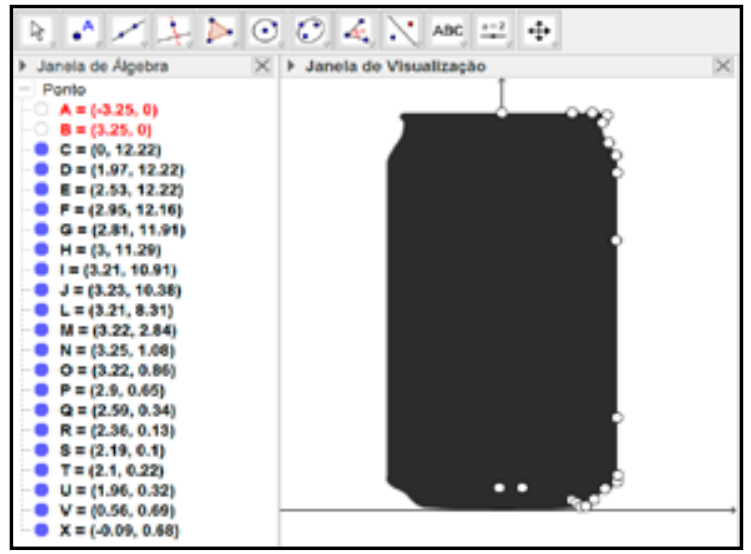

Figura 18 - Primeiro passo para a construção da curva sobre a silhueta do objeto 
A partir de todos os pontos construídos anteriormente, deve-se determinar uma curva descrita por uma equação paramétrica. Uma forma de produzir esse tipo de curva é utilizar o comando Spline [ $<$ Lista de Pontos $>$ ], ou seja, digita-se $a=\operatorname{Spline}[\{C, D, E, F, G, H, I, J, L, M, N, O, P, Q, R, S, T, U, V, X\}]$ no Campo Entrada. Note-se que o parâmetro do comando corresponde a uma lista delimitada por chaves e constituída por todos os pontos construídos sobre o contorno da silhueta.

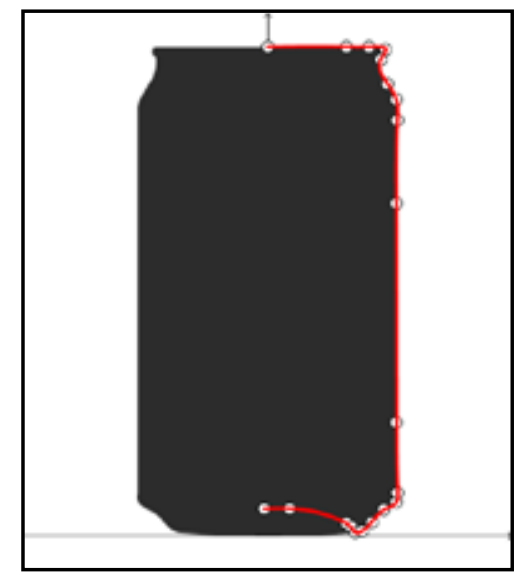

Figura 19 - Segundo passo para a construção da curva sobre a silhueta do objeto

Para uma melhor visualização, é interessante que sejam ocultados os pontos utilizados para a construção da curva. Em seguida, é construído um conjunto de pontos homogeneamente distribuídos sobre a curva. Para tanto, constrói-se um controle deslizante n, com mínimo 0, máximo 150 e incremento 1.

Em seguida, obtém-se uma lista $\mathrm{L}_{1}$ de $\mathrm{n}$ pontos sobre a curva a, digitando-se $L_{-} 1$ = Sequência[a( $)$, i, 0, 0.999, 1 / n] no Campo Entrada. A partir desse comando, obtém-se pontos que iniciam com o parâmetro 0 (zero), incremento 1/n e valor máximo 0.999: a $(0), a(0+1 / n), a(2 / n), \ldots, a(0.999)$.

Com a Janela de Visualização e a Janela de Visualização 3D lado a lado, observa-se o seguinte resultado.

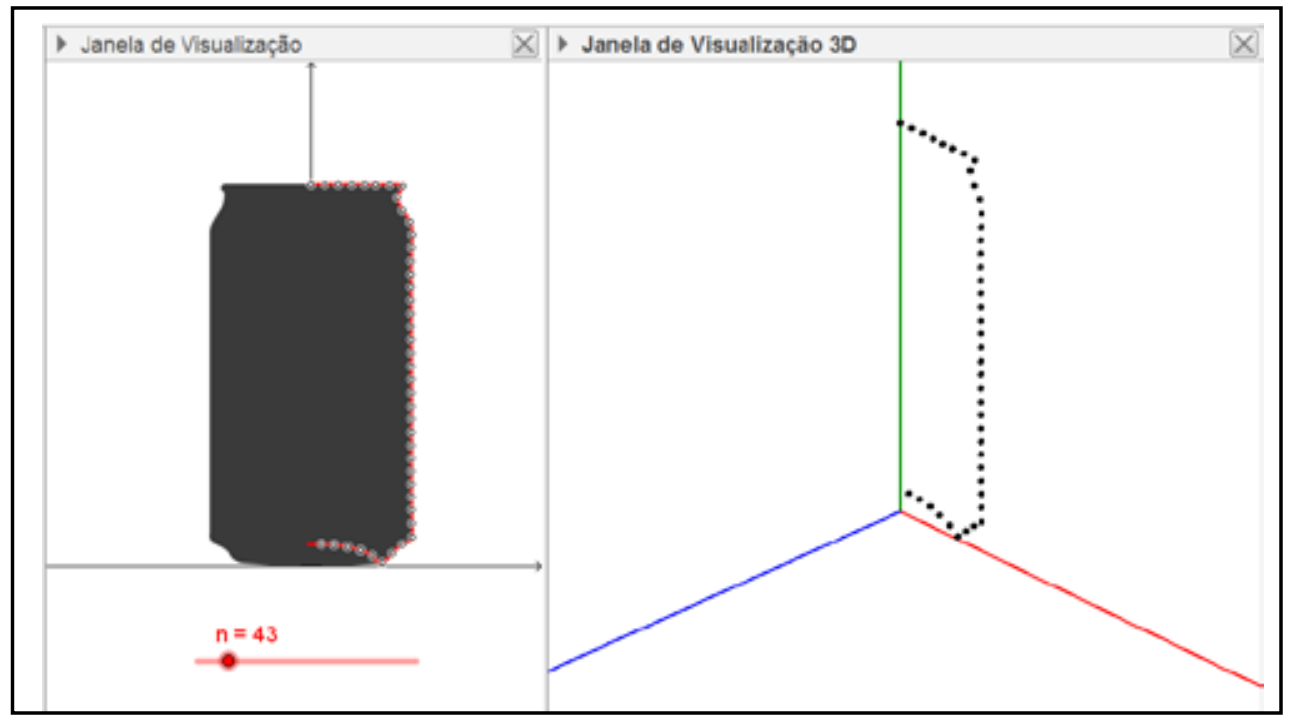

Figura 20 - Terceiro passo para a construção da curva sobre a silhueta do objeto

O eixo y pode ser visualizado na vertical na Janela de Visualização 3D. Para isso, seleciona-se a Janela de Visualização 3D, clica-se em Mover Janela, clica-se com o botão direito do mouse sobre qualquer local dessa janela e na opção Janela de Visualização. Na caixa que se abrir, na aba Básico, marca-se a opção "eixo y é vertical".

O próximo passo consiste em obter n círculos centrados no eixo y, passando pelos pontos da silhueta. Para tanto, no Campo Entrada, digita-se o seguinte comando: 


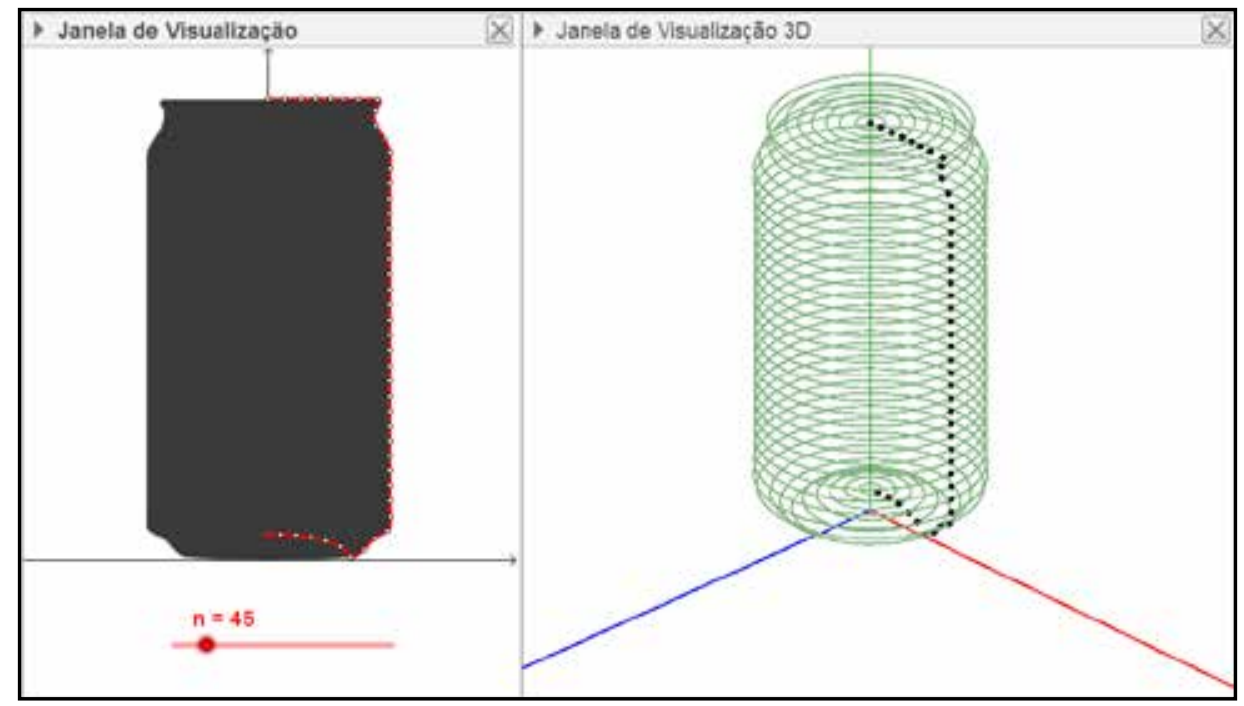

Figura 21 - Sequência de círculos

Na figura 21, é possível visualizar a sequência de círculos cujos centros estão sobre o eixo y.

Para determinar o volume do objeto obtido é necessário construir um polígono pelos n pontos sobre a curva, encontrar seu baricentro e utilizar o Teorema de Pappus, conforme abordado anteriormente. Para tanto, digita-se o comando Pol1 = Polígono[L_1] para construir o polígono, que tem como vértices os elementos de L. Digita-se também o comando Baricentro = CentroDeGravidade[Pol1] para determinar o centro de gravidade do polígono, como pode-se observar na Figura 22.

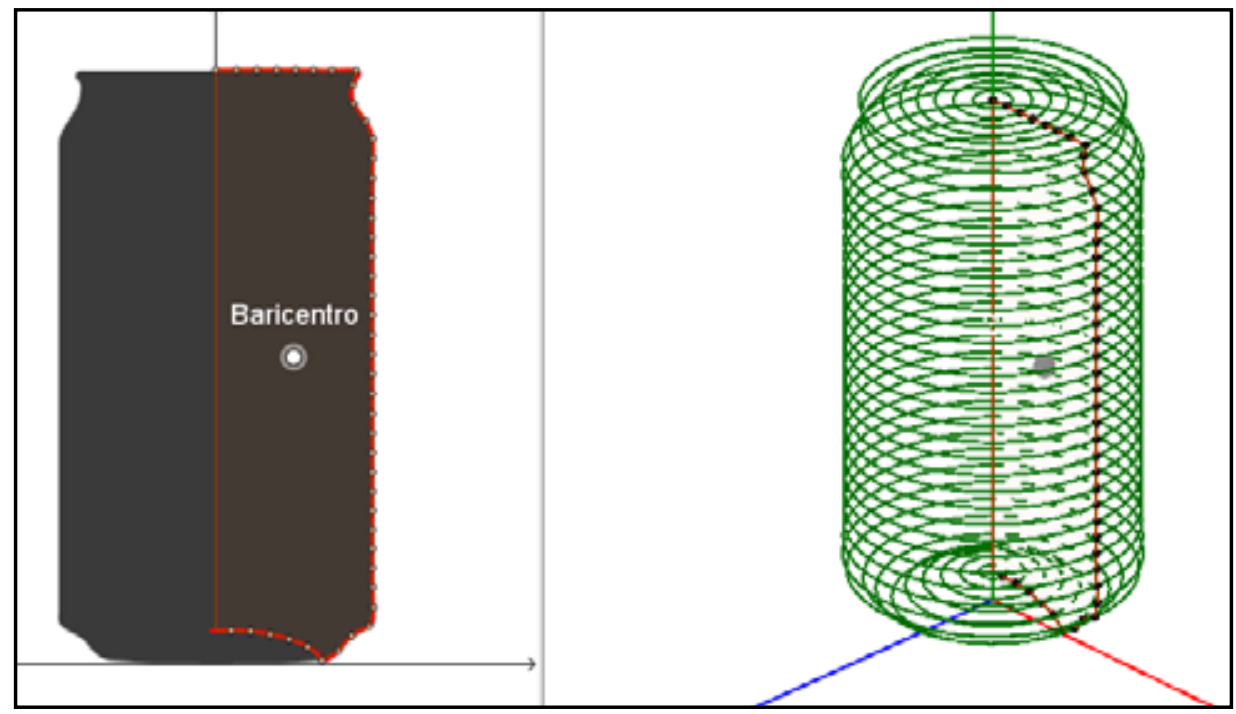

Figura 22 - Polígono e Baricentro

\section{Digitando Volume $=2 \pi *$ Pol1 * $x$ (Baricentro) no Campo Entrada, obtém-se o volume.}

Esse mesmo processo pode ser empregado para calcular o volume de outras formas de revolução, como garrafas, vasos, lâmpadas. Na Figura 23 é apresentada a modelação 3D a partir da silhueta de um vaso.

Outros exemplos são encontrados em Brandão et al. (2007) e Neves (2013). Há casos em que o volume foi calculado a partir do Teorema de Pappus, usando a fórmula do volume da esfera e, em outros, utilizando processos de integração.

A Figura 24 apresenta o processo de modelação de uma maçã de acordo com o processo descrito neste texto.

O cálculo do volume de uma maçã em relação ao cálculo de volume da lata de refrigerante apresenta uma diferença que deve ser ressaltada: a partir de uma foto da lata foi obtida uma imagem plana (silhueta) simétrica em relação a um eixo vertical a sua base e, o objeto tridimensional, a lata em si, corresponde a uma forma de revolução, o que não ocorre com a maçã, pois a tomada nesse exemplo não possui uma silhueta ${ }^{6}$ simétrica e a fruta, em geral, não corresponde a um objeto de revolução em sentido estrito. No entanto, o processo pode contribuir para obter uma boa aproximação de seu volume.

6 A imagem da maçã foi obtida por download de arquivo gratuito e com licença de uso em http://www.freepik.com. 


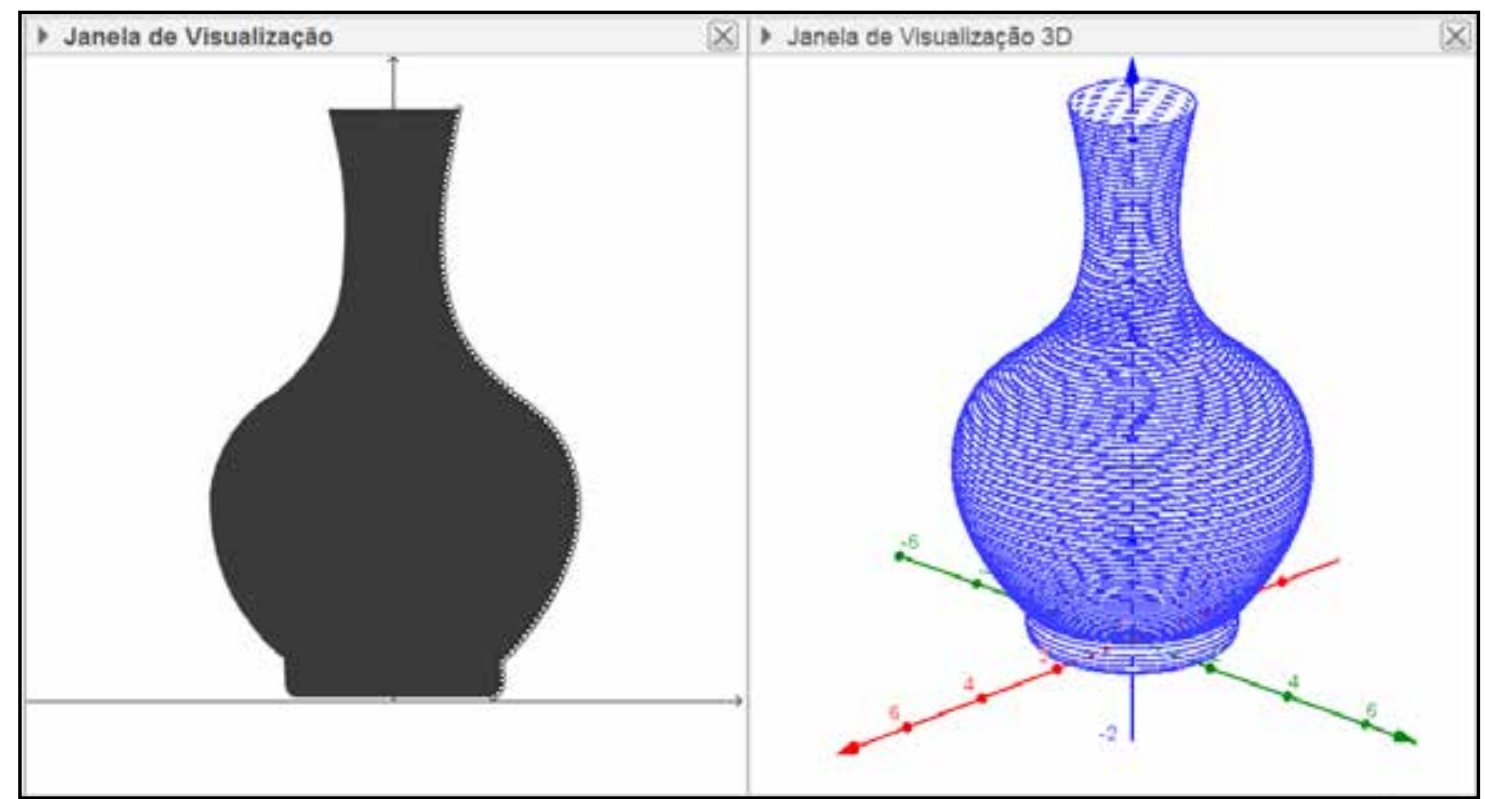

Figura 23 - Modelação de outros objetos

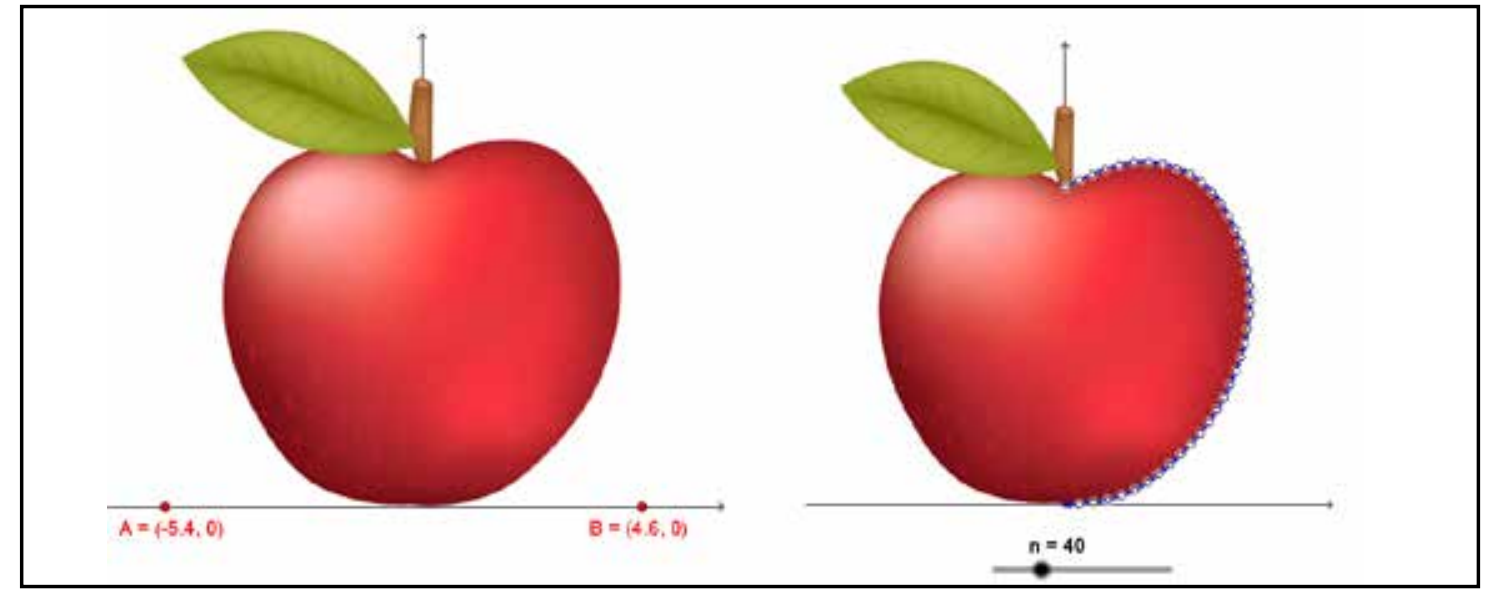

Figura 24 - Modelação de uma maçã

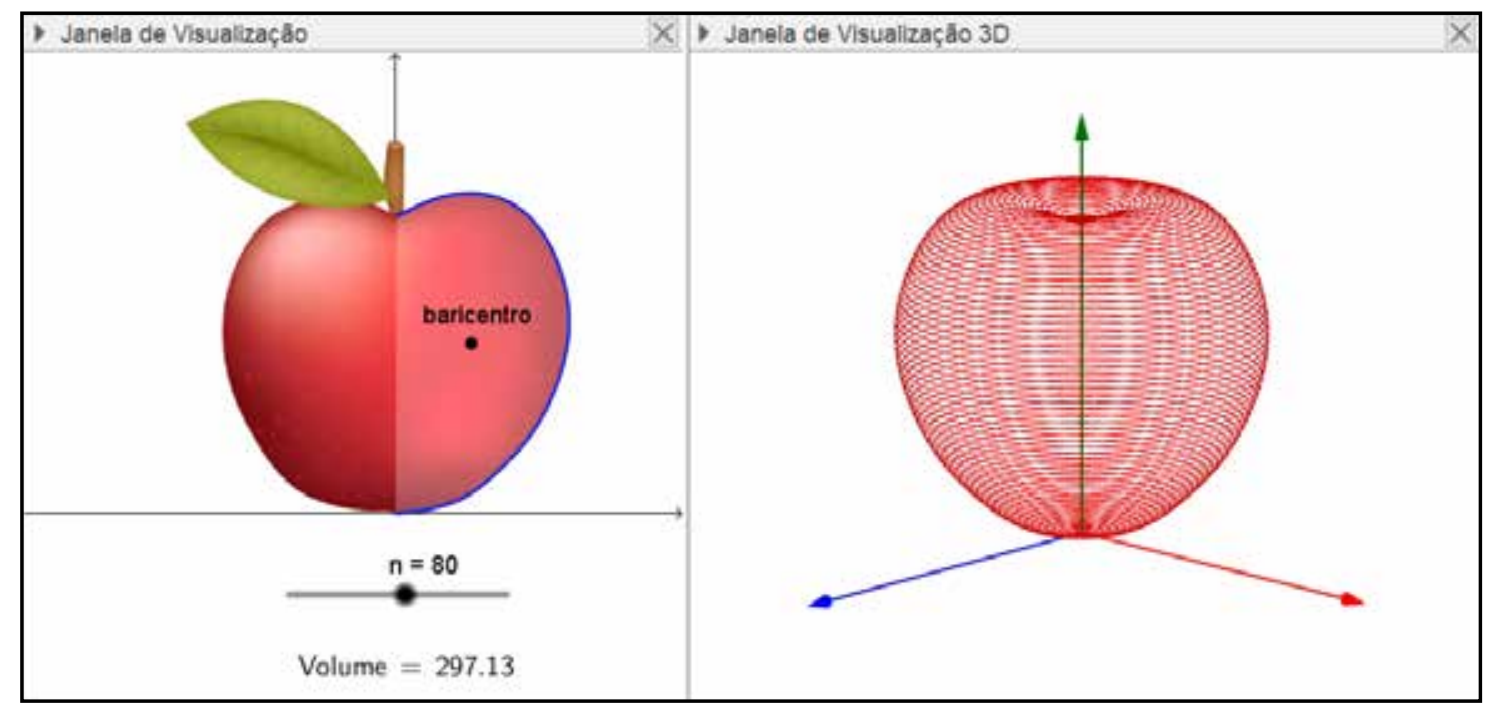

Figura 25 - Modelação e cálculo do volume de uma maçã 


\section{Conclusões}

Conforme explicitado na introdução, o objetivo deste texto foi apresentar uma sequência de atividades ou exemplos para refletir sobre o cálculo de volume e suas aplicações. Além disso, buscou-se propor uma possibilidade de trabalho a ser realizado com estudantes do Ensino Médio. Comumente, nesse nível de ensino, são trabalhados volumes de algumas formas de revolução, que em geral não possuem muitas aplicações para o cálculo de volumes de formas que aparecem no dia a dia dos estudantes. Assim, apresentou-se como problema motivador a determinação do volume de uma lata de refrigerante, cujo volume, geralmente, é de conhecimento dos estudantes, porém não é calculado em aulas de matemática como aplicação do estudo de cálculo de volume.

Pretendeu-se, com o auxílio de um software (GeoGebra), explorar as diferentes ferramentas que este possui, para que, a partir de poucos passos, os estudantes tenham a possibilidade de modelar e determinar volumes de formas distintas daquelas tradicionalmente apresentadas em materiais didáticos. Além disso, por meio da aplicação do Teorema de Pappus, tem-se a possibilidade de analisar aproximações numéricas e discutir as fórmulas clássicas de cálculo de volume.

\section{Referências}

ALMEIDA, L. M. W; MARTINS, N. Modelagem Matemática: uma aplicação usando a merenda escolar. Anais eletrônicos do VII ENEM - Encontro Nacional de Educação Matemática. Rio de Janeiro, 2001.

ANDRADE, L.N. Geometria Espacial com GeoGebra, Revista do Professor de Matemática, Rio de Janeiro, n. 87, 2015.

Balomenos, R., Ferrini-mundy, J. e Dick, T. Geometria: prontidão para o Cálculo. In M. Lindquist e A. Shulte (Org.). Aprendendo e Ensinando Geometria. (pp. 240-257). São Paulo: Atual Editora. 1994.

BRANDÃO, M. A. L.; DA SILVA, A. R.; TOGNON, C. H.; JAFELICE, R. S. da M. O uso da modelagem matemática no cálculo do volume de uma maçã. FAMAT em revista. p. 365-383, n.09, out-2007.

CURY, H. N., BISOGNIN, E. Calculando o volume de um sólido: como a análise de erros pode auxiliar professores a elaborar atividades de ensino para calouros de Engenharia. Anais: XXXIV - Congresso Brasileiro de Ensino de Engenharia. Passo Fundo: UPF, 2006.

DANTAS, S. C. GeoGebra: Formas de revolução a partir de polígonos. Disponível em https://youtu.be/Apd-xOojQs. Publicado em 20 de novembro de 2015. Acesso: fev-2016.

DANTAS, S. C.; FERREIRA, G. F. Criando e Integrando novas ferramentas no GeoGebra. Revista do Professor de Matemática, Rio de Janeiro, n. 85, 2014.

DANTE, L. R. Matemática: contexto e aplicações. Vol. 1, 2 e 3. São Paulo: Ática, 2010.

LIMA, E. L.; CARVALHO, P. C. P.; WAGNER, E.; MORGADO, A. C. A Matemática no Ensino Médio - volume 2. Publicação SBM, 2006.

MENEZES, J. C. de. Áreas e volumes: uma abordagem complementar ao livro "A matemática do ensino médio" SBM - vol. 2, E. L. LIMA, et al.. 2015. 96 f. Dissertação (Mestrado Profissional em Matemática) - Universidade Federal de Sergipe, Itabaiana, 2015.

NEVES, J.M. Uso de modelagem Matemática no cálculo da área da superfície e do volume de uma maçã. Dissertação de Mestrado - Programa de Mestrado Profissional em Matemática em Rede Nacional - PROFMAT, Universidade Federal do Piauí. Teresina, 2013.

PAIVA, M. Matemática - Paiva. Vol. 1, 2 e 3. Ed. - São Paulo: Moderna, 2009.

RAUTENBERG, R. R. OS TEOREMAS DE PAPPUS PARA OS SÓLIDOS DE REVOLUÇÃO. Dissertação de Mestrado - Programa de Mestrado Profissional em Matemática em Rede Nacional - PROFMAT, Universidade Tecnológica Federal do Paraná. Curitiba, 2013. 